\title{
KEKAYAAN DAN POTENSI SENYAWA BIOAKTIF MAKROALGA DI PESISIR ATEP OKI, KABUPATEN MINAHASA, SULAWESI UTARA
}

(Wealth and Potential of Macroalgae Bioactive Compounds on the Atep Oki Coast, District of Minahasa, North Sulawesi)

\section{Silsia Dorkas Winowoda*, Marina Flora Oktavine Singkoh, Ratna Siahaan}

Program Studi Biologi, Fakultas Matematika dan Ilmu Pengetahuan Alam Universitas Sam Ratulangi, Manado.

*e-mail: silsiadorkas@gmail.com

\begin{abstract}
This study aims to analyze the richness and potential of macroalgae bioactive compounds on the Atep Oki Coast, District of Minahasa, North Sulawesi Province. This research was conducted in October 2019 until January 2020. Sampling used the roaming method in a predetermined location that is Atep Oki tidal/ intertidal coast. Sampling locations are spread over six coordinate points. Macroalgae found on the Atep Oki Coast assessed ten species belonging to three phyla, namely Chlorophyta (green algae), Ochrophyta (brown algae) and Rhodophyta (red algae). Chlorophyta members mean six species. Ochrophyta has members of three species and members of Rhodophyta only one species. The types of macroalgae found on the Atep Oki Coast provide bioactive compounds.
\end{abstract}

Keywords : Macroalgae, Bioactive Compounds, Atep Oki Minahasa Coast

\section{Abstrak}

Penelitian ini bertujuan untuk menganalisis kekayaan jenis dan potensi senyawa bioaktif makroalga di Pesisir Atep Oki, Kabupaten Minahasa, Provinsi Sulawesi Utara. Penelitian ini telah dilaksanakan pada bulan Oktober 2019 sampai Januari 2020. Pengambilan sampel menggunakan metode jelajah di lokasi yang telah ditentukan yaitu pesisir pasang surut/intertidal Atep Oki. Lokasi pengambilan sampel tersebar di enam titik-titik koordinat. Makroalga yang ditemukan di Pesisir Atep Oki berjumlah sepuluh species yang tergolong ke dalam tiga filum yaitu Chlorophyta (alga hijau), Ochrophyta (alga cokelat) dan Rhodophyta (alga merah). Anggota Chlorophyta berjumlah enam species. Ochrophyta memiliki anggota tiga species dan anggota Rhodophyta hanya satu species. Jenis-jenis makroalga yang ditemukan di Pesisir Atep Oki berpotensi menghasilkan senyawa bioaktif.

Kata kunci : Makroalga, Senyawa Bioaktif, Pesisir Atep Oki Minahasa 


\section{PENDAHULUAN}

Perairan Indonesia memiliki sumber daya laut yang berpotensi besar untuk dimanfaatkan, salah satunya yaitu alga. Alga merupakan tumbuhan laut tingkat rendah berklorofil yang dapat melakukan proses fotosintesis dengan bantuan cahaya matahari, yang memiliki fungsi sebagai tempat pembesaran dan pemijahan biota-biota laut mencegah pergerakan substrat, dan sebagai penyaring air (Dwimayasan dan Kurnianto, 2018). Berdasarkan morfologi, alga tidak bisa dibedakan antara bagian akar, batang, maupun daun sehingga seluruh bagian tubuhnya disebut talus. Keberadaan dan pertumbuhan alga dipengaruhi oleh faktor lingkungan diantaranya ketersediaan nutrisi (nitrat dan fosfat), salinitas, suhu, substrat, arus, dan cahaya (Kasim, 2016).

Berdasarkan perananya pada rantai makanan suatu perairan, alga termasuk organisme autotrof (penghasil makanan sendiri). Alga berperan sebagai produsen primer yaitu bahan-bahan organik seperti polisakarida, hormon, vitamin, dan mineral yang dapat dimanfaatkan sebagai sumber makanan maupun sumber senyawa bioaktif (Muchtaridi, 2016). Sumber makanan yang dihasilkan seperti agar, keraginan, dan alginat. Sumber senyawa bioaktif yang merupakan golongan senyawa metabolit sekunder dari alga misalnya flavonoid, alkaloid, tanin, saponin, triterpenoid, steroid, fenol, kumarin, dan glikosida (Firdhayani et al., 2014).

Perairan Indonesia dihuni oleh sekitar 782 alga laut yang tersusun atas 196 jenis alga hijau, 134 jenis alga coklat, dan 452 jenis alga merah. Alga telah lama dimanfaatkan manusia sebagai sumber makanan dan obat. Sejumlah 61 jenis telah dimanfaatkan manusia sebagai sumber obat. Alga tersebut termasuk ke dalam 15 jenis alga hijau, 8 jenis alga cokelat, dan 38 alga merah (Kepel et al., 2019).

Penelitian ini bertujuan untuk menganalisis kekayaan jenis dan potensi senyawa bioaktif makroalga di Pesisir Atep Oki, Kabupaten Minahasa, Provinsi Sulawesi Utara.

\section{METODE PENELITIAN}

\section{Waktu dan Tempat Penelitian}

Penelitian ini dilaksanakan pada bulan Oktober 2019 sampai Januari 2020. Pengambilan sampel dilaksanakan di Pesisir Atep Oki, Desa Atep Oki, Kecamatan Lembean Timur, Kabupaten Minahasa, Sulawesi Utara (Gambar 1). Sampel lalu diindentifikasi di Laboratorium Lanjut, Jurusan Biologi Fakultas Matematika dan IImu Pengetahuan Alam, Universitas Sam Ratulangi, Manado, Sulawesi Utara.

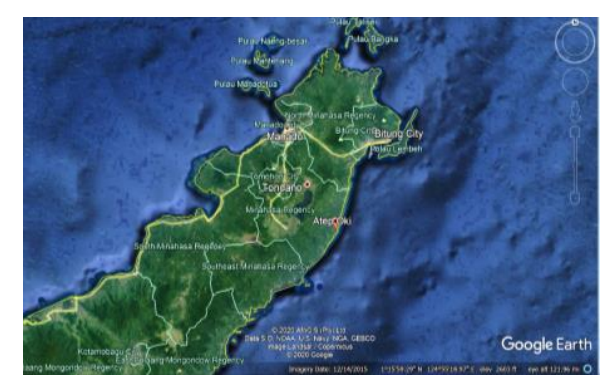

Gambar 1. Peta Lokasi

\section{Prosedur Penelitian}

Penelitian eksploratif dengan mengumpulkan data di lapangan. Hasil Ialu dianalis secara deskriptif untuk menganalisis kekayaan jenis dan potensi bioaktif makroalga yang ditemukan. Pengumpulan data dilakukan dengan mengambil sampel di lapangan. Metode 
pengambilan sampel yaitu metode jelajah di lokasi yang telah ditentukan yaitu pesisir pasang surut/intertidal Atep Oki.

Pengambilan sampel dilakukan saat surut terjauh. Setiap makroalga yang ditemukan dikoleksi. Sampel selanjutnya difoto di lapangan. Identifikasi dan klasifikasi dilakukan di Laboratorium Biologi Lanjut, Jurusan Biologi FMIPA Universitas Sam Ratulangi. Identifikasi dengan menggunakan pustaka antara lain Guiry, 2020 dan Trono \& Ganzon-Fortes, 1988. Pengambilan data faktor fisik dan kimia dilakukan sesaat di lapangan. Data lingkungan yang diukur yaitu $\mathrm{pH}$ dan salinitas. Data substrat diperoleh dengan pengamatan langsung di lapangan. Potensi senyawa bioaktif dari tiap makroalga yang ditemukan dengan menggunakan berbagai pustaka. Acuan pustaka ini khususnya pustaka senyawa bioaktif dari makroalga yang ditemukan di Indonesia khsusunya di Sulawesi Utara.

\section{HASIL DAN PEMBAHASAN}

Lokasi pengambilan sampel tersebar di enam titik-titik koordinat yaitu $A O 1$ (01'09'10.1"LU dan 12501'30.9"BT), AO2

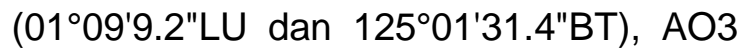
(01'09'08.6"LU dan 12501'32.0"BT), AO4 (01'09'10.3"LU dan 12501'34.2"BT), AO5 (01'09'09.8"LU dan 12501'34.6"BT), AO6

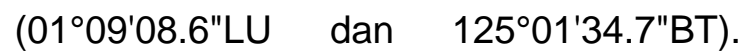
Pengambilan sampel dari pesisir paling dekat ke daratan hingga ke pesisir terjauh yang dekat dengan laut lepas (Gambar 2).

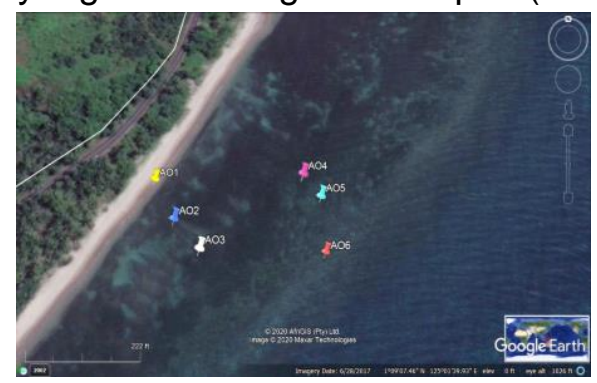

Gambar 2. Titik-titik Koordinat
Makroalga yang ditemukan berada di ekosistem lamun. Makroalga hidup bersama-sama Pengamatan dilakukan saat surut terjauh sehingga pengamatan mudah dilakukan. Lamun yang ditemukan yaitu Syringodium, Cymodocea dan Enhalus. Lebar zona pengamatan sekitar $150 \mathrm{~m}$ dan panjang zona sekitar $100 \mathrm{~m}$. Air di lokasi pengamatan memiliki $\mathrm{pH}$ kisaran 7- 8, salinitas 30 hingga $36 \%$. Salinitas semakin tinggi mendekati laut lepas. Hal ini disebabkan air daratan yang tawar memasuki air laut sehingga air laut di dekat daratan lebih rendah salinitasnya dibandingkan yang lebih ke laut. Substrat di lokasi pengamatan berupa pasir hingga pecahan karang yang telah mati (Gambar 3).

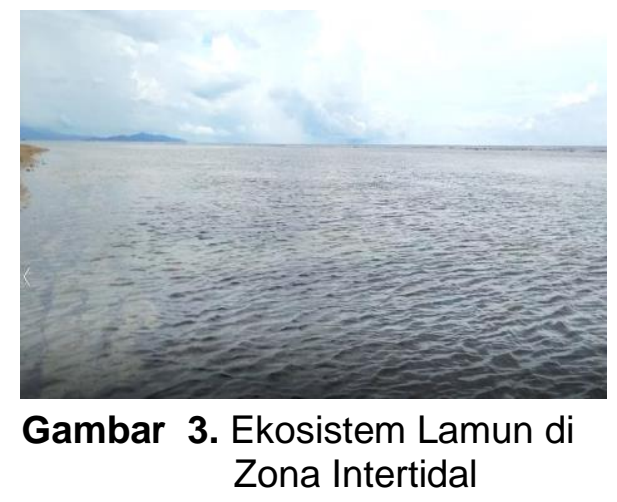

\section{Kekayaan Jenis Makroalga}

Makroalga yang ditemukan di lokasi penelitian terbagi ke dalam tiga kelompok yaitu alga hijau, alga coklat dan alga merah. Jumlah total makroalga yang ditemukan sebanyak 10 spesies (Tabel 1). Alga hijau sejumlah enam jenis yaitu alga Halimeda macroloba, Halimeda incrassata, Dictyosphaeria cavernosa, Avrainvillea erecta, Bornetella sphaerica Valonia aegagropila. Alga cokelat ada tiga jenis yaitu alga Turbinaria decurrens, Padina australis, dan Sargassum polycystum. Alga merah yang ditemukan satu jenis yaitu Tricleocarpa fragilis. 
Table 1. Klasifikasi Makroalga

\begin{tabular}{|c|c|c|c|}
\hline No & Spesies & & Klasifikasi \\
\hline 1 & $\begin{array}{l}\text { Halimeda } \\
\text { macroloba }\end{array}$ & $\begin{array}{l}\text { Kingdom } \\
\text { Phylum } \\
\text { Subphylum } \\
\text { Class } \\
\text { Order } \\
\text { Family } \\
\text { Genus } \\
\text { Species }\end{array}$ & $\begin{array}{l}\text { : Plantae } \\
\text { : Chlorophyta } \\
\text { : Chlorophytina } \\
\text { : Ulvophyceae } \\
\text { : Bryopsidales } \\
\text { : Halimedaceae } \\
\text { : Halimeda } \\
\text { : Halimeda macroloba } \\
\text { (Decaisne) }\end{array}$ \\
\hline 2 & $\begin{array}{l}\text { Halimeda } \\
\text { incrassata }\end{array}$ & $\begin{array}{l}\text { Kingdom } \\
\text { Phylum } \\
\text { Subphylum } \\
\text { Class } \\
\text { Order } \\
\text { Family } \\
\text { Genus } \\
\text { Spesies }\end{array}$ & $\begin{array}{l}\text { : Plantae } \\
\text { : Chlorophyta } \\
\text { : Chlorophytina } \\
\text { : Ulvophyceae } \\
\text { : Bryopsidales } \\
\text { : Halimedaceae } \\
\text { : Halimeda } \\
\text { : Halimeda incrassata (J. Ellis) } \\
\text { J.V.Lamouroux }\end{array}$ \\
\hline 3 & $\begin{array}{l}\text { Dictyosphaeria } \\
\text { cavernosa }\end{array}$ & $\begin{array}{l}\text { Kingdom } \\
\text { Phylum } \\
\text { Subphylum } \\
\text { Class } \\
\text { Order } \\
\text { Family } \\
\text { Genus } \\
\text { Spesies }\end{array}$ & $\begin{array}{l}\text { : Plantae } \\
\text { : Chlorophyta } \\
\text { : Chlorophytina } \\
\text { : Ulvophyceae } \\
\text { : Cladophorales } \\
\text { : Siphonocladaceae } \\
\text { : Dictyosphaeria } \\
\text { : Dictyosphaeria cavernosa } \\
\text { (Forsskål) Børgesen }\end{array}$ \\
\hline 4 & Avrainvillea erecta & $\begin{array}{l}\text { Kingdom } \\
\text { Phylum } \\
\text { Subphylum } \\
\text { Class } \\
\text { Order } \\
\text { Family } \\
\text { Genus } \\
\text { Spesies }\end{array}$ & $\begin{array}{l}\text { : Plantae } \\
\text { : Chlorophyta } \\
\text { : Chlorophytina } \\
\text { : Ulvophyceae } \\
\text { : Bryopsidales } \\
\text { : Dichotomosiphonaceae } \\
\text { : Avrainvillea } \\
\text { : Avrainvillea erecta (Berkeley) } \\
\text { A.Gepp \& E.S.Gepp }\end{array}$ \\
\hline 5 & $\begin{array}{l}\text { Bornetella } \\
\text { sphaerica }\end{array}$ & $\begin{array}{l}\text { Kingdom } \\
\text { Phylum } \\
\text { Subphylum } \\
\text { Class } \\
\text { Order } \\
\text { Family } \\
\text { Genus } \\
\text { Spesies }\end{array}$ & $\begin{array}{l}\text { : Plantae } \\
\text { : Chlorophyta } \\
\text { : Chlorophytina } \\
\text { : Ulvophyceae } \\
\text { : Dasycladales } \\
\text { : Dasycladaceae } \\
\text { : Bornetella } \\
\text { : Bornetella sphaerica } \\
\text { (Zanardini) Solms-Laubach }\end{array}$ \\
\hline
\end{tabular}


Tabel 1. Klasifikasi Makroalga (Lanjutan)

\begin{tabular}{|c|c|c|c|}
\hline No & Spesies & & Klasifikasi \\
\hline 6 & $\begin{array}{l}\text { Valonia } \\
\text { aegagropila }\end{array}$ & $\begin{array}{l}\text { Kingdom } \\
\text { Phylum } \\
\text { Subphylum } \\
\text { Class } \\
\text { Order } \\
\text { Family } \\
\text { Genus } \\
\text { Species }\end{array}$ & $\begin{array}{l}\text { : Plantae } \\
\text { : Chlorophyta } \\
\text { : Chlorophytina } \\
\text { : Ulvophyceae } \\
\text { : Cladophorales } \\
\text { : Valoniaceae } \\
\text { : Valonia } \\
\text { : Valonia aegagropila C. } \\
\text { Agardh }\end{array}$ \\
\hline 7 & $\begin{array}{l}\text { Turbinaria } \\
\text { decurrens }\end{array}$ & $\begin{array}{l}\text { Kingdom } \\
\text { Phylum } \\
\text { Class } \\
\text { Subclass } \\
\text { Order } \\
\text { Family } \\
\text { Genus } \\
\text { Spesies }\end{array}$ & $\begin{array}{l}\text { : Chromista } \\
\text { : Ochrophyta } \\
\text { : Phaeophyceae } \\
\text { : Fucophycidae } \\
\text { : Fucales } \\
\text { : Sargassaceae } \\
\text { : Turbinaria } \\
\text { : Turbinaria decurrens Bory }\end{array}$ \\
\hline 8 & Padina australis & $\begin{array}{l}\text { Kingdom } \\
\text { Phylum } \\
\text { Class } \\
\text { Subclass } \\
\text { Order } \\
\text { Family } \\
\text { Genus } \\
\text { Spesies }\end{array}$ & $\begin{array}{l}\text { : Chromista } \\
\text { : Ochrophyta } \\
\text { : Phaeophyceae } \\
\text { : Dictyotophycidae } \\
\text { : Dictyotales } \\
\text { : Dictyotaceae } \\
\text { : Padina } \\
\text { : Padina australis Hauck }\end{array}$ \\
\hline 9 & $\begin{array}{l}\text { Sargassum } \\
\text { polycystum }\end{array}$ & $\begin{array}{l}\text { Kingdom } \\
\text { Phylum } \\
\text { Class } \\
\text { Subclass } \\
\text { Order } \\
\text { Family } \\
\text { Genus } \\
\text { Spesies }\end{array}$ & $\begin{array}{l}\text { : Chromista } \\
\text { : Ochrophyta } \\
\text { : Phaeophyceae } \\
\text { : Fucophycidae } \\
\text { : Fucales } \\
\text { : Sargassaceae } \\
\text { : Sargassum } \\
\text { : Sargassum polycystum } \\
\text { J. Agardh }\end{array}$ \\
\hline 10 & $\begin{array}{l}\text { Tricleocarpa } \\
\text { fragilis }\end{array}$ & $\begin{array}{l}\text { Kingdom } \\
\text { Phylum } \\
\text { Subphylum } \\
\text { Class } \\
\text { Subclass } \\
\text { Order } \\
\text { Family } \\
\text { Genus } \\
\text { Spesies }\end{array}$ & $\begin{array}{l}\text { : Plantae } \\
\text { : Rhodophyta } \\
\text { : Eurhodophytina } \\
\text { : Florideophyceae } \\
\text { : Nemaliophycidae } \\
\text { : Nemaliales } \\
\text { :Galaxauraceae } \\
\text { : Tricleocarpa } \\
\text { : Tricleocarpa fragilis (L.) } \\
\text { Huisman \& R.A.Townsend }\end{array}$ \\
\hline
\end{tabular}


Alga Hijau Halimeda macroloba (Decaisne) 1841

Halimeda adalah genus makroalga hijau yang penting, terkalsifikasi dan berasosiasi dengan habitat terumbu karang tropis. Spesies Halimeda tersebar luas di seluruh terumbu pada daerah subtidal dan pada kedalaman lebih dari $100 \mathrm{~m}$ dan dapat membentuk populasi dalam jumlah besar. Sekitar $75 \%$ dari spesies halimeda lebih suka pada habitat kerikil daripada pasir atau lumpur.

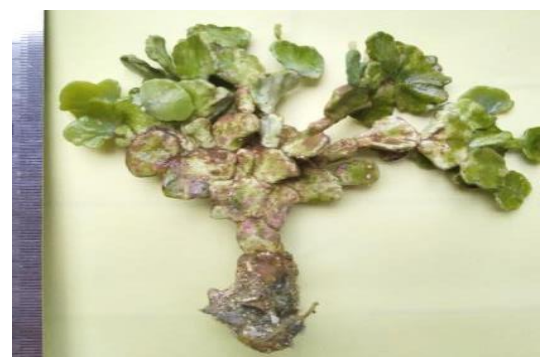

Gambar 4. Halimeda macroloba

Talus membentuk blade seperti kipas. Talus tegak, segmen besar, dan rata. Tepian segmen berombak atau membentuk lobus tidak teratur (Trono dan Ganzon-Fortes, 1988). Hidup di perairan substrat pasir berbatu (Leibo et al., 2016).

\section{Alga Hijau Halimeda incrassata (J.Ellis) J.V.Lamouroux 1816}

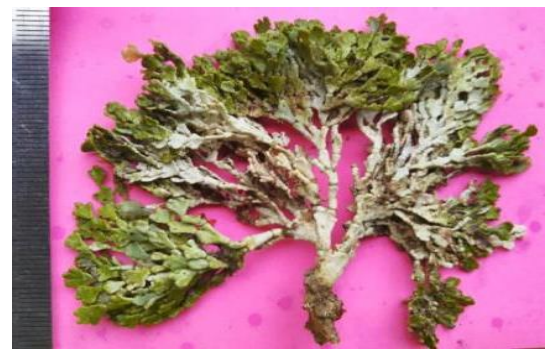

Gambar 5. Halimeda incrassata
Makroalga tegak lurus, tinggi 5- 6,5 $\mathrm{cm}$ dan lebar 7-9 cm, berwarna hijau muda, bersegmen padat dan berkapur. Blade berbentuk seperti kipas dan rimbun. Percabangan utama dikotom. Holdfast berbentuk seperti umbi yang berwarna kecokelatan. Hidup pada substrat berpasir dan karang mati (Pongparadon, 2009).

\section{Alga Hijau Dictyosphaeria cavernosa (Forsskål) Børgesen 1932}

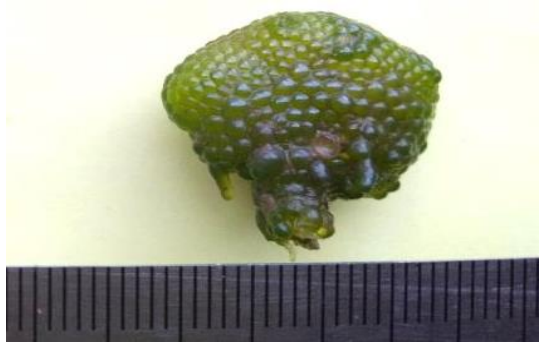

\section{Gambar 6. Dictyosphaeria cavernosa}

Bentuk talus padat, berwarna hijau, berdiameter $2-5 \mathrm{~cm}$, lobus tidak teratur, berdinding tebal dan menggumpal, memiliki holdfast rhizoid yang berukuran kecil yang terdapat di bagian bawah permukaan talus. Organ ini berfungsi sebagai alat pelekat (Van Aalderen-Zen, 2016). Dictyosphaeria cavernosa atau alga gelembung hijau ini termasuk alga invasif dalam komunitas terumbu karang yang bernutrisi tinggi. Alga $D$. cavernosa ditemukan melekat pada pecahan karang di dataran dangkal, karang mati dan daerah pasang surut (Anonim, 2001; Van Aalderen-Zen, 2016). 
Alga Hijau Avrainvillea erecta (Berkeley) A.Gepp \& E.S.Gepp 1911

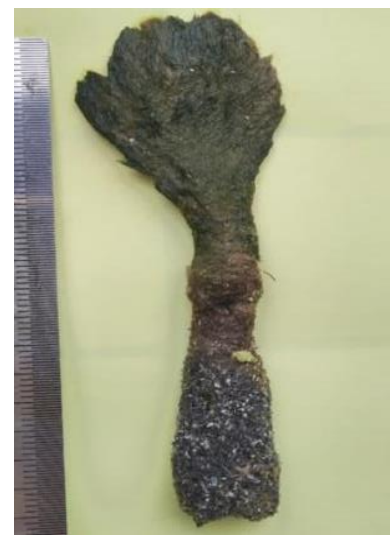

Gambar 7. Avrainvillea erecta

Talus berbentuk seperti pedang, tegak, agak tebal, halus, berwarna hijau tua dan memiliki tinggi 1-6 cm, lebar 2,5$10 \mathrm{~cm}$. Blade terdiri dari filamen-filamen yang tidak keras, dan sangat lembut. Holdfast berbentuk seperti umbi (Titlyanov et al., 2018). Alga hijau ini dapat tetap hidup di lumpur disebabkan alga memiliki holdfast yang dapat masuk hingga ke bagian dalam sedimen lumpur (Zainee et al., 2019).

\section{Alga Hijau Bornetella sphaerica} (Zanardini) Solms-Laubach 1892

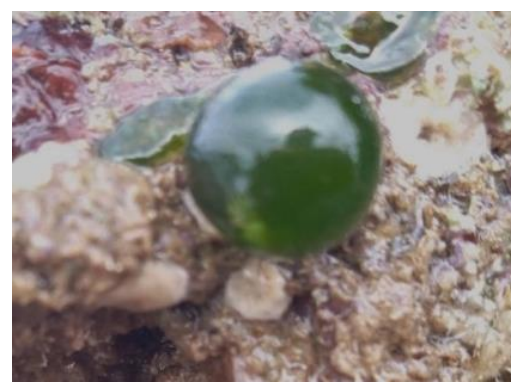

Gambar 8. Bornetella sphaerica

Talus tidak berkapur tinggi (Trono \& Ganzon-Fortes, 1988). Alga hidup soliter. Bentuk talus oval seperti buah pir/sperikal, berwarna hijau tua, berukuran kecil dengan tinggi $0,5-1 \mathrm{~cm}$. Alga ini menancap pada substrat dengan holdfast seperti cakram. (Titlyanov et al., 2018). Alga ini menyukai habitat lamun di substrat pecahan karang (Ohba et al., 2017).

\section{Alga Hijau Valonia aegagropila C. Agardh 1823}

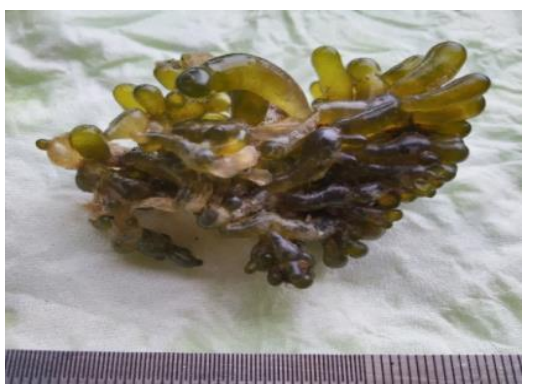

Gambar 9. Valonia aegagropila

Talus mempunyai bentuk yang lurus, berwarna hijau kecokelatan, vesikula tidak beraturan, bergerombol dan belapis-lapis. Memiliki holdfast rhizoid terletak di permukaan bawah talus. Spesies zona mid-litoral yang menghuni daerah intertidal dangkal (Chaudhury et al., 2019), substrat batu dan karang mati (Trono, 2016).

\section{Alga Coklat Turbinaria decurrens Bory 1828}

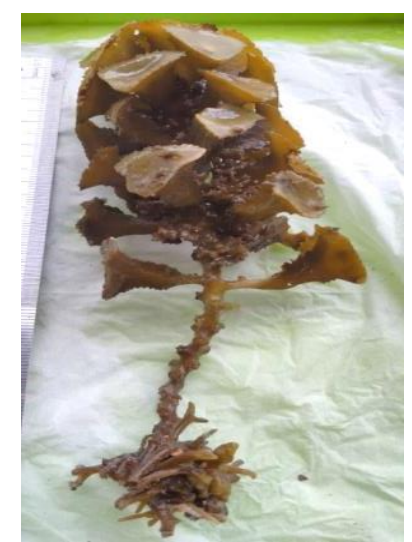

Gambar 10. Turbinaria decurrens

Talus tegak. Daun berbentuk segitiga/trigonous yang tampak jelas (Trono \& Ganzon-Fortes, 1988). Holdfast terbentuk sperti rhizoid. memiliki bagian yang menyerupai untaian bunga pada 
stipe. Habitat alga ini dapat tumbuh di bebatuan, karang mati di daerah intertidal ke subtidal (Titlyanov et al., 2018).

\section{Alga Coklat Padina australis Hauck 1887}

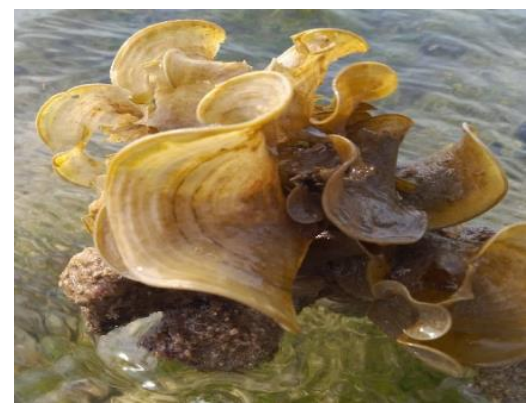

Gambar 11. Padina australis

Talus menyerupai kipas membentuk lobus. Blade datar dan terbelah, ujung menggulung, memiliki garis-garis radial di permukaan bawah, berwarna cokelat muda. Holdfast tunggal. Berwarna coklat keputihan adanya kalsifikasi (JIRCAS, 2012). Menempati daerah intertidal hingga subtidal di substrat batu dan karang mati (Hawai'l, 1996).

Alga Coklat Sargassum polycystum C. Agardh 1824

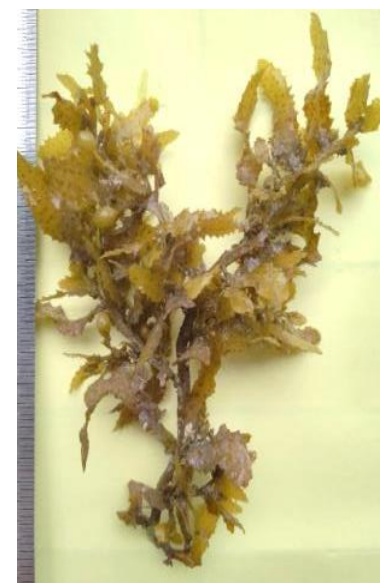

Gambar 12. Sargassum polycystum

Daun rata, melebar dan memiliki tulang daun utama/midrib (Trono \& Ganzon-Fortes, 1988). Talus berukuran besar dengan tinggi dapat mencapai 40 $\mathrm{cm}$, berwarna cokelat tua hingga cokelat kekuningan, stipe berbentuk bulat kasar, tepi blade bergerigi dan ujung meruncing. Alga ini memiliki gelembung udara (bladder) yang soliter, berukuran kecil, bulat seperti telur, dan berdiameter 2-2,5 $\mathrm{mm}$. Alga ini tumbuh subur pada substrat batu karang (Trono, 2001).

\section{Alga Merah Tricleocarpa fragilis} (Linnaeus) Huisman \& R. A. Townsend 1993

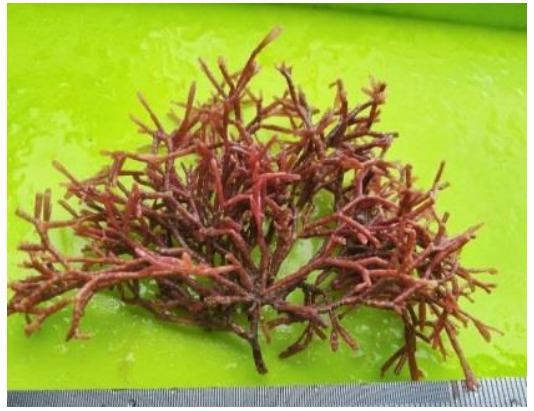

Gambar 13. Tricleocarpa fragilis

Talus mudah patah, rimbun, berwarna ungu muda, tinggi $6-12 \mathrm{~cm}$, percabangan dikotom teratur yang terdiri dari segmen berbentuk silinder dan halus dengan panjang 5-6 mm. Holdfast berukuran kecil dan tidak berbentuk (Titlyanov et al., 2018). Habitat alga ini berupa substrat batu dan karang mati (Titlyanov et al., 2018), cangkang moluska dan di daerah intertidal (Guiry, 2020).

\section{KESIMPULAN}

Makroalga yang ditemukan di Pesisir Atep Oki berjumlah sepuluh species yang tergolong kedalam tiga filum yaitu Chlorophyta (alga hijau), Ochrophyta (alga coklat) dan Rhodophyta (alga merah). Anggota Chlorophyta berjumlah enam species. Ochrophyta memiliki anggota tiga species dan anggota Rhodophyta hanya satu species. 


\section{DAFTAR PUSTAKA}

Chaudhury, N.R., Shangvy D., Jain B. 2019. Macroalgaespecies as zonal indicators of coral reef: a case study from Bet Shankhodhar Reef, India in Gokce, D. Weland Management:Assesing Risk and Sustanaible Solutions. London : IntechOpen. pp. 45-55.

Dwimayasanti, R., Kurnianto, D. 2018. Komunitas Makroalga Di Perairan Tayando-Tam, Maluku Tenggara. Jurnal Oseanologi dan Limnologi di Indonesia 3(1): 39-48.

Firdhayani, I.N., Alamsjah, M.A., S. Subekti. 2014. Eksplorasi Bahan Aktif Rumput Laut Coklat (Phaeophyceae) sebagai Biolarvasida Aedes aegypti. Jurnal IImiah Perikanan dan Kelautan 6(2): 187-192.

Guiry, M.D. 2020. Tricleocarpa fragilis (Linnaeus) Huisman \& R.A.Townsend 1993. In Guiry, M.D. \& Guiry, G.M. 2020. AlgaeBase. World-wide electronic publication, National University of Ireland, Galway. $\quad$ http://www.algaebase.org; Diakses 14 Juli 2020.

Hawai'I, H. 1996. Marine Plants of Hawai'i. In Hawai'I, H. 2015. Coralreefnetwork. Hawai'l Coral Reef Network. http://www.coralreefnetwork.com/marlife/s eaweeds/dictyo.htm; Diakses 16 Juli 2020.

JIRCAS. 2012. Padina australis Hauck. https://www.jircas.affrc.go.jp/project/quacul $\mathrm{t}$ Thailand/data/padina australis.html.

Diakses 25 Juli 2020.

Kasim, M. 2016. Kajian Biologi, Ekologi, Pemanfaatan dan Budidaya Makro Alga. Penebar Swadaya, Jakarta Timur.
Kepel, R. C., Lumingas, L.J.L., Watung, P.M.M., Mantiri, D.M.H. 2019. Community structure of seaweeds along the intertidal zone of Mantehage Island, North Sulawesi, Indonesia. Bioflux, 12(1): 87101.

Leibo, R., Mantiri, D.M.H., dan G.S. Gerung. 2016. Uji Aktivitas Antioksidan dari Ekstrak Total Alga Hijau Halimeda Opuntia Linnaeus dan Halimeda Macroloba Decaisne Dari Perairan Teluk Totok. Jurnal Pesisir dan Laut Tropis 2(1): 30-36.

Muchtaridi, M.N. 2016. Aktivitas Antimikroba dari Senyawa Bioaktif Rumput Laut atau Makroalga. Jurnal Farmaka Suplemen 15(2): 207-217.

Ohba, H., Matsuda, S., Asami, R., Iryu, Y. 2017. Recent Dasycladales (Chlorophyta) in Okinawa Jima in the Central Ryukyus, southwestern Japan: Paleontological implications. Island Arc. 26: e12185.

Pongparadon, S. 2009. Diversity, Distribution and Variations within Species of Genus Halimeda J.V.Lamour. (Chlorophyta) in Peninsular Thailand [Tesis]. Faculty of Science, Prince of Songkla University, Thailand.

Titlyanov, E.A., Titlyanova, T.V., O.S Belous. 2018. Useful Marine Plants Of The Asia-Pacific Region Countries. A.V. Zhirmunsky National Scientific Center for Marine Biology FEB RAS, Vladivostok.http://www.imb.dvo.ru; Diakses 15 Juli 2020.

Trono G.C., Ganzon-Fortes E. T. 1988. Philippines seaweeds, Technology and livelihood center PCPM Certificate of registration No. SP 594. 
Trono, G.C. 2001. Seaweeds.. In Capenter, K.E. and V.H. Niem. The Living Marine Resources of the Western Central Pacific, Vol. 1. FAO Species Identification Guide for Fishery Purposes. Rome, FAO. Pp. 19-99.

Trono, G.C. 2016. Valonia aegagropila (PROSEA). Plant Resources of SouthEast Asia. https://uses.plantnetproject.org; Diakses 15 Juli 2020.

Van Aalderen-Zen, P.Y. 2016. Dictyosphaeria cavernosa (PROSEA). Plant Resources of South-East Asia. https://uses.plantnet-project.org; Diakses 15 Juli 2020.

Zainee, N.F.A., Ismail, A., Taip, M.E., Ibrahim, N., Ismai, A. 2019. Habitat preference of seaweeds at a tropical island of southern Malaysia. Songklanakarin J. Sci. Technol. 41(5): 1171-1177. 